\title{
Atuação dos aleloquímicos no organismo vegetal e formas de utilização da alelopatia na agronomia
}

\author{
Paulo Sérgio Siberti da Silva \\ PPG em Agronomia-Horticultura \\ Universidade Estadual Paulista "Júlio de Mesquita Filho", Campus de Botucatu \\ Avenida Padre Almeida Garret, 390, CEP 13087-290, Campinas - SP, Brasil \\ sibertisilva@hotmail.com
}

Submetido em 01/02/2012

Aceito para publicação em 08/06/2012

\section{Resumo}

No reino vegetal, tanto em florestas quanto em agrossistemas, ocorre a alelopatia, que é o efeito benéfico ou maléfico de uma planta sobre a outra, mediante liberação de compostos secundários. O fenômeno é determinante no processo de formação das comunidades vegetais, servindo, também, como importante ferramenta para a agronomia, pois seu uso pode promover o combate de plantas indesejáveis, manter as culturas sadias e solucionar casos de insucessos dos cultivares. Além disso, os bioensaios alelopáticos contribuem para a identificação de possíveis fontes botânicas de compostos com ação biocida para combate de pragas e doenças. Logo esse fenômeno pode proporcionar ao pequeno produtor a mudança na sua maneira de se relacionar com a terra e diminuir ou até mesmo abolir o uso de defensivos químicos em suas propriedades. O atual trabalho se trata de uma revisão de literatura sobre algumas formas de atuação dos aleloquímicos no organismo vegetal e maneiras de utilização da alelopatia no manejo e cultivo de plantas.

Palavras-chave: Agricultura; Bioatividade; Metabólitos secundários

\section{Abstract}

Allelochemicals in plants and the use of allelopathy in agronomy. Within the plant kingdom, allelopathy occurs in forests and in agroecosystems, which can produce beneficial or harmful effects on plants that are related to the release of secondary metabolites. This phenomenon influences the formation of plant communities in natural environments and also serves as an important tool in agronomy because it can be used to control undesirable plants, maintain healthy cultures, and can help save failing crops. Furthermore, allelopathic bioassays contribute to the identification of possible sources of biocide compounds that can be used to combat pests and diseases. These biocides can help eliminate the use of agrochemicals and change the way small producers influence their land. The present work is a literature review that focuses on some plant allelochemicals and the use of allelopathy during plant cultivation.

Key words: Agriculture; Bioactivity; Secondary metabolites 


\section{Introdução}

Desde há muito tempo o homem já tem conhecimento de que determinadas espécies vegetais, quando em uma mesma área, interferem no desenvolvimento das outras, sendo a origem de tais eventos justificada por fenômenos de difícil explicação (VIANA et al., 2001). Além disso, muitos agricultores verificavam que, com o passar do tempo, suas lavouras sofriam uma queda de produtividade, situação denominada pelos mesmos de "cansaço da terra", e para amenizar este problema, utilizava-se o pousio, repouso das áreas cultiváveis, como método para a restauração do terreno (ALMEIDA, 1988).

Sabe-se hoje que muitas causas de baixa produtividade estão relacionadas a alelopatia, a palavra é oriunda da união das palavras allélon e pathos, significando, mútuo e prejuízo, respectivamente (ALMEIDA, 1988). O termo foi criado por Hans Molisch (1937, apud RIZVI; RIZVI, 1992), e o fenômeno é definido como a influência benéfica ou maléfica de um indivíduo, planta ou microrganismo, sobre outro, mediada por biomoléculas denominadas aleloquímicos (RIZVI; RIZVI, 1992).

No vegetal, tais compostos são oriundos do metabolismo secundário e são liberados no ambiente via exsudados radiculares no solo ou por substâncias voláteis no ar, tendo como exemplos dos principais grupos de aleloquímicos os fenóis, terpenos, alcalóides e poliacetilenos (RIZVI; RIZVI, 1992; SOUZA-FILHO, 2006).

Na natureza estes compostos podem influenciar no crescimento e desenvolvimento de sistemas biológicos circundantes (RAZAVI, 2011), se tratando, de um importante fator ecológico, pois atuam na formação das comunidades vegetais (SEVERINO et al., 2008).

Um determinado metabólito secundário pode ter diferentes efeitos, prejudiciais ou benéficos, dependendo do seu tipo, grupo funcional, propriedade química e concentração no meio que está atuando (BARBOSA et al., 2005; GOLDFARB et al., 2009). Além disso, os efeitos destes compostos podem depender das condições climáticas e do tipo de solo onde se encontram, podendo se transformar em outros compostos (ALMEIDA, 1988), e alguns metabólitos só atuam em presença de outros, atuando em sinergismo, pois não atingem a concentração mínima necessária para exercer o efeito alelopático (ALMEIDA, 1988).

Os metabólitos secundários diferem dos primários, pois apresentam especificidade, estando restritos a determinadas espécies vegetais, atuando na defesa contra herbívoros e atração de polinizadores para a planta (TAIZ; ZEIGER, 2009). Desta maneira, todas as plantas os produzem, porém, variam em quantidade e qualidade de espécie para espécie. A tolerância ou resistência a estes compostos também pode ser específica, havendo espécies mais sensíveis que outras, como por exemplo, o alface (Lactuca sativa L.) e o tomate (Solanum lycopersicum L.), que são usadas em bioensaios de alelopatia como espécies bioindicadoras (FERREIRA; AQUILA, 2000).

Muitas vezes o fenômeno da alelopatia é confundido com competição, pelo fato de que, em determinadas situações, ambos influenciam no crescimento e/ou desenvolvimento da planta circundante. Contudo, na alelopatia ocorre adição de um fator biológico ao meio ambiente, já na competição, há remoção ou redução de algum fator ambiental (água, luz, nutrientes, etc.), necessário para o crescimento de ambas as plantas que os disputam (ZANINE; SANTOS, 2004).

$\mathrm{Na}$ agricultura, os estudos alelopáticos podem ser de grande importância, servindo para desvendar muitas causas de insucessos dos cultivares que não obtiveram o desempenho esperado, se tornando uma importante e vantajosa ferramenta para a agronomia (SOUZAFILHO, 2006; GOLDFARB et al., 2009).

Plantas possuidoras de compostos com atividade alelopática inibitória podem ser utilizadas como herbicidas naturais eficientes, controlando plantas daninhas, e também, servindo como indicativos para possíveis fontes de novos compostos com ação biocida, contribuindo para o aumento da produtividade e permanência sadia dos cultivares, tornando a área de cultivo mais equilibrada (PIÑA-RODRIGUES; LOPES, 2001; REZENDE et al., 2003; MAIRESSE et al., 2007; APPLETON; BERRIER, 2009).

Mas é necessária a orientação dos produtores a respeito da necessidade do conhecimento das 
propriedades e especificidades químicas de cada espécie cultivada em sua área, ao passo que, tanto para um manejo agrícola, florestal ou na horticultura, a ocupação prévia de uma área pode exercer influência significativa para as espécies que serão instaladas (FERREIRA; ÁQUILA, 2000).

Assim, tendo caráter informativo, o atual trabalho se trata de uma revisão de literatura sobre algumas formas de atuação dos aleloquímicos no organismo vegetal e maneiras de utilização da alelopatia no manejo e cultivo de plantas.

\section{Efeito dos aleloquímicos e formas de utilização da alelopatia na agronomia}

Dentre os estádios do desenvolvimento vegetal influenciados pelos aleloquímicos, a germinação é a menos sensível, ao passo que a sua quantificação experimental é muito mais simples, pois a semente germina ou não germina (FERREIRA; ÁQUILA, 2000).

No campo, os efeitos alelopáticos negativos sobre a germinação levam à desuniformidade da cultura, uma vez que os aleloquímicos podem proporcionar estresse oxidativo, formando espécies reativas de oxigênio, como $\mathrm{o}_{2} \mathrm{O}_{2}$, que atua de forma direta ou como sinalizador nos processos de degradação celular, causando danos em processos fisiológicos e alterando o desenvolvimento inicial das plântulas (ALMEIDA et al., 2008).

Além disso, alterações nos padrões de germinação refletem em alterações de rotas metabólicas inteiras e modificam processos importantes para o desenvolvimento do embrião, afetando sua ontogênese (FERREIRA; ÁQUILA, 2000). Estas alterações podem estar relacionadas com efeitos sobre a permeabilidade de membranas, transcrição e tradução de material genético, as reações enzimáticas e a respiração celular (RIZVI; RIZVI, 1992).

A avaliação do crescimento das plântulas também é um instrumento valioso durante o desenvolvimento do cultivo, uma vez que os aleloquímicos induzem o aparecimento de plântulas anormais, tendo como sintoma mais comum a necrose radicular (FERREIRA; ÁQUILA, 2000).
Entre os efeitos alelopáticos mais comuns constatados na bibliografia corrente sobre o crescimento vegetal, é destacada a interferência dos aleloquímicos na divisão celular, síntese orgânica, interações hormonais, absorção de nutrientes, inibição da síntese de proteínas, mudanças no metabolismo lipídico, abertura estomática, assimilação de $\mathrm{CO}_{2}$ e na fotossíntese, inibindo o transporte de elétrons e reduzindo o conteúdo de clorofila na planta (REZENDE et al., 2003; REIGOSA et al., 2006).

Já na rizosfera, os aleloquímicos podem desencadear mudanças na relação água-planta, promovendo distúrbios nas membranas das células das raízes, causando diminuição significativa da biomassa vegetal e área foliar (REIGOSA et al., 2006).

Em consequência destes efeitos alelopáticos, alterações no desempenho e produtividade das culturas são observadas, e alguns agricultores passam a usufruir da propriedade alelopática das plantas, denominadas "bioativas", como uma forma estratégica para a produção sustentável de alimentos, usando-as em consorciamento com espécies cultivadas, onde, além de evitar o crescimento de espécies invasoras buscam também combater os nematóides do solo (SCHIEDECK, 2008), como observado por Amaral et al. (2001), onde mudas de café (Coffea arabica L.) com seis meses de idade que receberam extrato metanólico de cebola (Allium cepa L.) e extrato aquoso de arruda (Ruta graveolens L.), em diferentes períodos de tempo, 15 e 30 dias, respectivamente, apresentaram uma redução significativa do número de galhas do nematóide Meloidogyne exigua Goeldi.

Outro foco de ação destes produtos é o combate aos insetos, como apontado por Restello et al. (2009), que observaram o efeito repelente e inseticida do óleo essencial de cravo-de-defunto (Tagetes patula L.) na concentração de $10 \mu \mathrm{L}$ sobre Sitophilus zeamais Motschulsky (Coleoptera, Curculionidae), em milho (Zea mays L.) armazenado sob condições de laboratório. O mesmo foi verificado por Almeida et al. (1999) ao constatar que os extratos vegetais de pimenta-do-reino (Piper nigrum L.), laranja (Citrus vulgaris Risso.), cróton (Croton tiglium L.) e crisântemo (Chrysanthemum spp.) controlaram os insetos adultos de Sithophilus 
spp. em 100, 99, 98 e 97\%, respectivamente, quando aplicados na forma de vapor em grãos de milho.

Com o objetivo de avaliar a bioatividade de espécies vegetais que possam, assim, contribuir como fontes de aleloquímicos, Mairesse et al. (2007) verificaram que os extratos brutos aquosos na dosagem de $1 / 3(\mathrm{p} / \mathrm{v})$ de salso-chorão (Salix humboldtiana Willd.), jambolão [Syzygium cuminii (L.) Skeels], fumo-bravo (Solanum erianthum D. Don) e chá-de-bugre (Casearia sylvestris Sw.) inibiram o crescimento das plântulas de alface e os extratos de falso-boldo (Plecthranthus barbatus Andr.), guajuvira (Patagonula americana L.), tiririca (Cyperus rotundus L.), babosa (Aloe arborescens Mill.) e açoita-cavalo (Luehea divaricata Mart.) estimularam o crescimento da mesma, mostrando uma potencial ação alelopática das espécies.

Estudando a bioatividade do extrato aquoso de folhas frescas de nim (Azadirachta indica A. Juss.), em laboratório, Rickli et al. (2011) verificaram uma diminuição significativa da porcentagem de germinação de alface quando suas sementes foram submetidas aos extratos com concentração a partir de $40 \%$, ao passo que o comprimento de raiz também foi influenciado de forma significativa em todas as concentrações de extratos (Figura 1).

Os autores também observaram interferência alelopática significativa dos extratos de nim sobre o comprimento das raízes de feijão (Phaseolus vulgaris L.) e milho, a partir da concentração de $20 \%$ de extrato (Figuras 2 e 3).

No entanto, testes em campo são essenciais para a comprovação da intensidade dos efeitos alelopáticos (CORSATO et al., 2010), pois no meio ambiente os aleloquímicos podem ser transformados, pela ação de microrganismos ou outros fatores presentes no estrato superior do solo, em compostos com propriedades químicas totalmente diferentes, que podem ser benéficos ou maléficos para as plantas circundantes (FERREIRA; BORGUETTI, 2004).

FIGURA 1: Plântulas de alface (Lactuca sativa L.) submetidas ao extrato aquoso de folhas de nim (Azadirachta indica A. Juss.) (T1) Testemunha. (T2) Extrato a 20\%. (T3) Extrato a 40\%. (T4) Extrato a 60\%. (T5) Extrato a 80\%. (T6) Extrato a 100\%. Fotos em escalas diferentes. Extraído de Rickli et al. (2011).

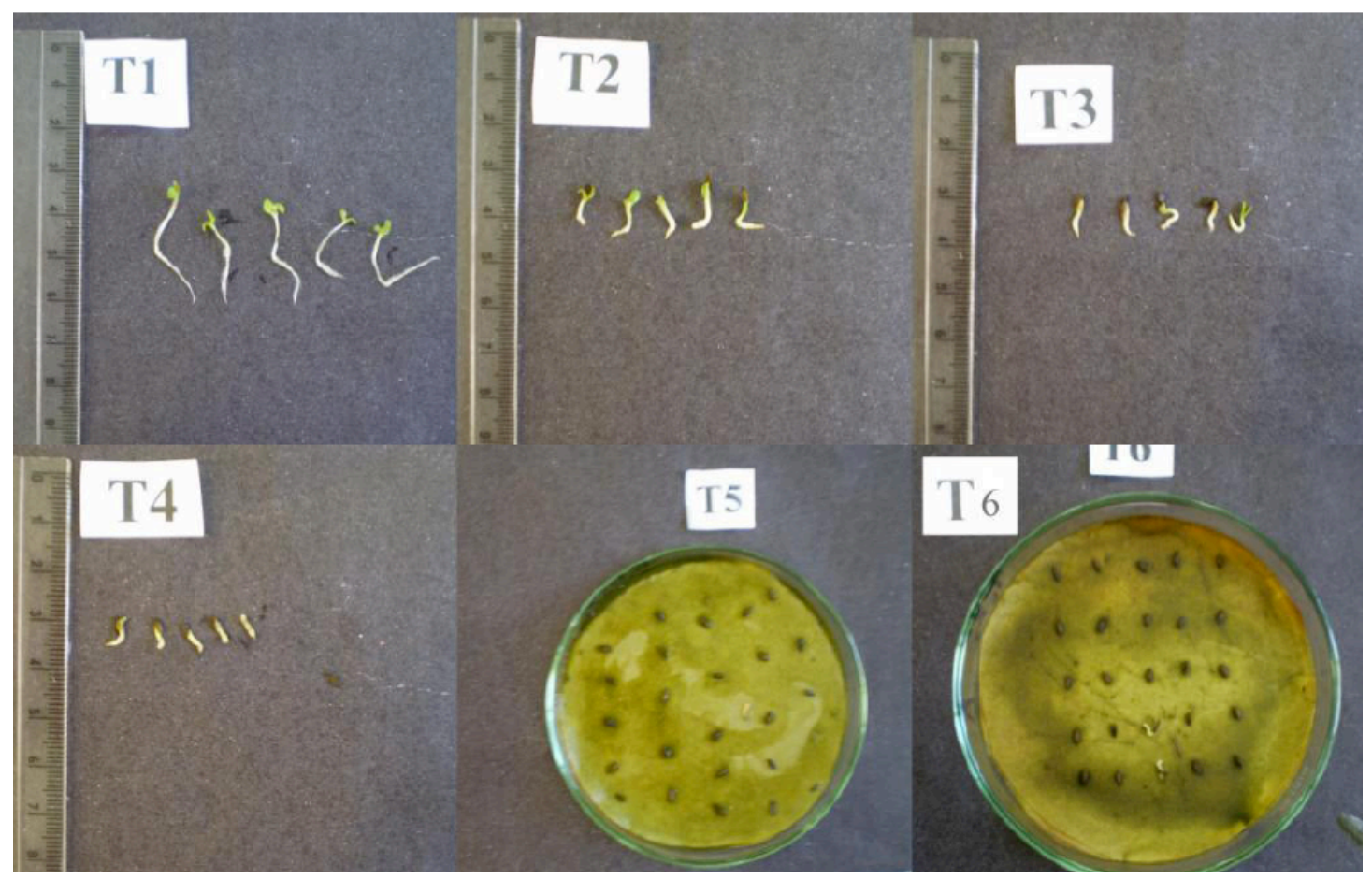


FIGURA 2: Plântulas de feijão (Phaseolus vulgaris L.) submetidas ao extrato aquoso de folhas de nim (Azadirachta indica A. Juss.) (T1) Testemunha. (T2) Extrato a 20\%. (T3) Extrato a 40\%. (T4) Extrato a 60\%. (T5) Extrato a 80\%. (T6) Extrato a 100\%. Extraído de Rickli et al. (2011).

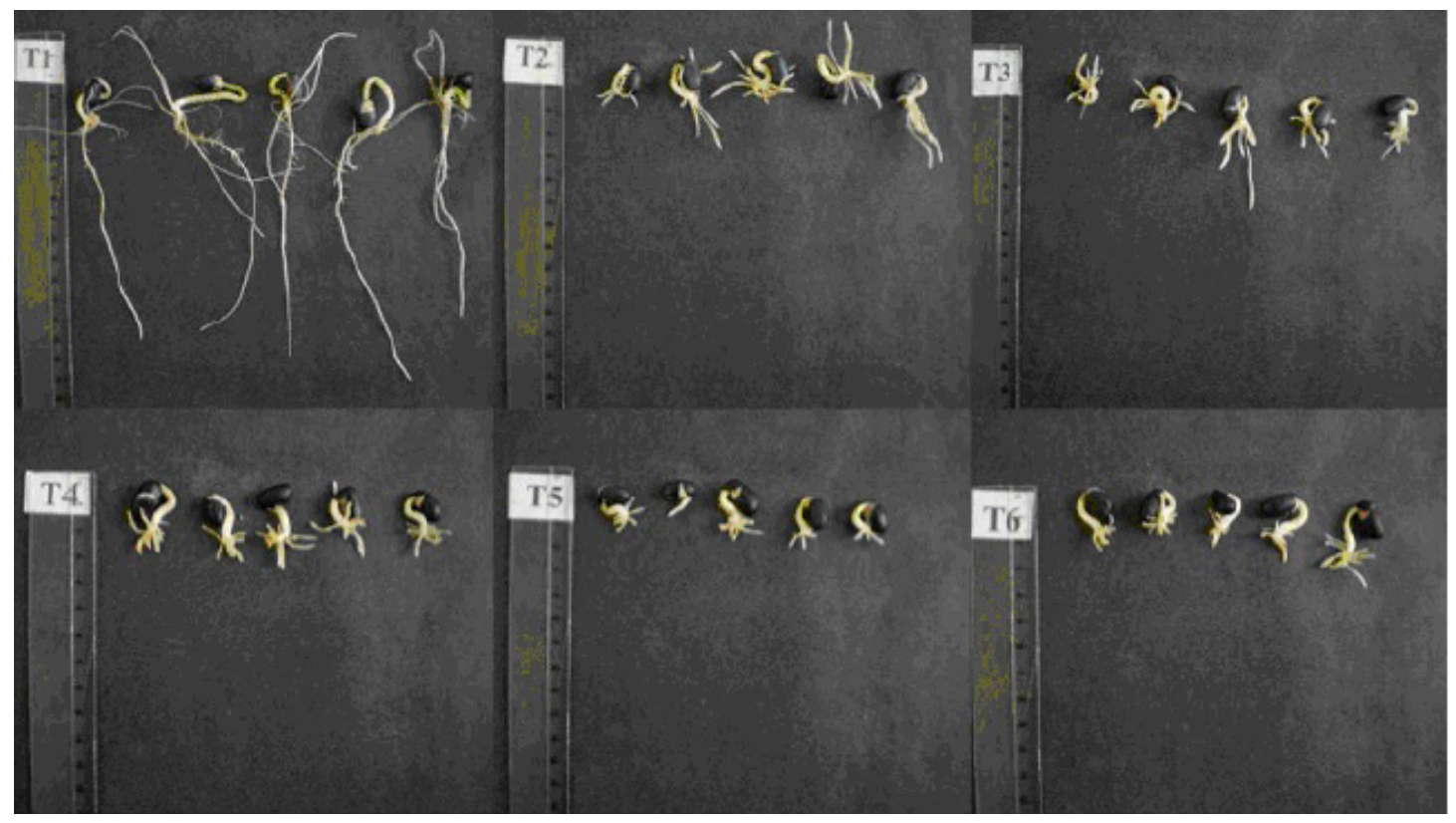

FIGURA 3: Plântulas de milho (Zea mays L.) submetidas ao extrato aquoso de folhas de nim (Azadirachta indica A. Juss.) (T1) Testemunha. (T2) Extrato a 20\%. (T3) Extrato a 40\%. (T4) Extrato a 60\%. (T5) Extrato a 80\%. (T6) Extrato a 100\%. Extraído de Rickli et al. (2011).

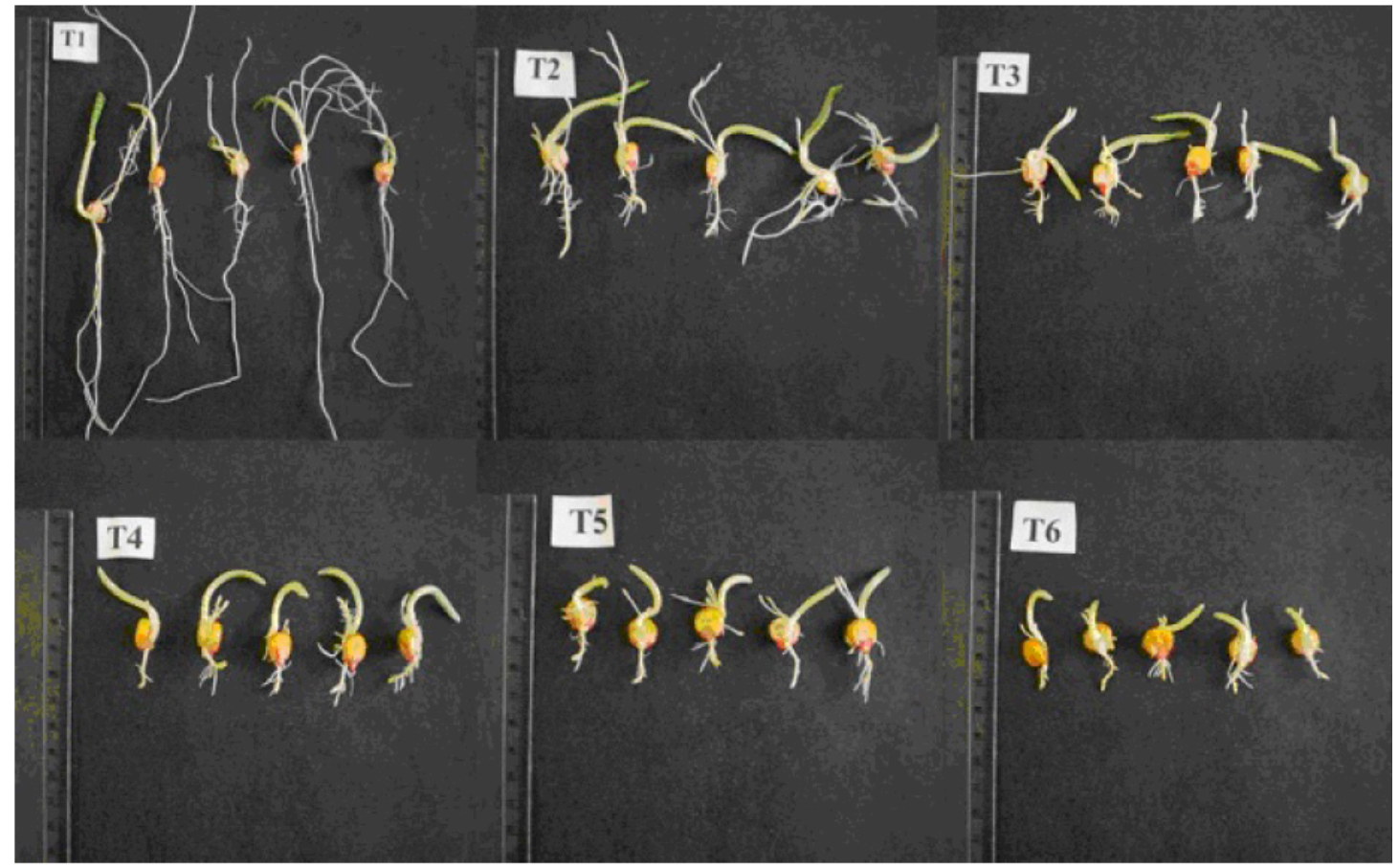


No Brasil, uma técnica muito recomendada e praticada pelos agricultores é a rotação de culturas, onde se faz um rodízio de cultivos, ou seja, numa época do ano planta-se uma determinada espécie e na seguinte outra, mas, dependendo da cultura utilizada na rotação, tal método pode passar a ser uma limitação, devido à incorporação dos restos da cultura anterior no solo, que podem exercer efeitos alelopáticos danosos no cultivo seguinte, afetando seu crescimento e produtividade (FERREIRA; ÁQUILA, 2000).

No entanto, escolhendo de forma correta as plantas, melhorias podem ser observadas no desenvolvimento dos cultivares, tal como o trabalho realizado por França et al. (2007) que, utilizando palhada dos híbridos de milho GNZ 200, DKB 350, GNZ 2004 e P30K75 sobre diferentes cultivares de cafeeiro em casa-de-vegetação, verificaram, aos 90 dias após o plantio um incremento na área foliar dos cafeeiros que receberam palhas incorporadas (Tabela 1). Os autores alegam que, além do efeito benéfico da retenção de umidade do solo pela palhada e liberação de nitrogênio resultante de sua decomposição, o efeito benéfico das incorporações de palhas em relação à testemunha também pode ser ocasionado devido à liberação de aleloquímicos.
TABELA 1: Área foliar total de plantas de café (Coffea arabica $\mathrm{L}$.), em função da palhada dos híbridos de milho (Zea mays L.) GNZ 2005, DKB 350, GNZ 2004 e P30K75 incorporados aos 90 dias após o plantio. Universidade Federal de Lavras, MG. Adaptado de França et al. (2007).

\begin{tabular}{lc}
\hline \multirow{2}{*}{ Incorporação } & Área foliar $\left(\mathbf{d m}^{\mathbf{2}}\right)$ \\
\cline { 2 - 2 } & $\mathbf{9 0}$ dias \\
\hline GNZ 2005 & $9,70 \mathrm{~b}$ \\
DKB 350 & $9,75 \mathrm{~b}$ \\
GNZ 2004 & $10,87 \mathrm{a}$ \\
P30K75 & $9,71 \mathrm{~b}$ \\
Testemunha & $8,83 \mathrm{c}$ \\
\hline
\end{tabular}

Médias seguidas da mesma letra não diferem entre si pelo teste Scott-Knott a $5 \%$ de probabilidade.

Na bibliografia corrente existem vários trabalhos que relatam o controle de plantas daninhas através de extratos vegetais, como o trabalho realizado por Pires et al. (2001), onde foi observado, em casa-de-vegetação, que, sete dias após a aplicação dos extratos de leucena [Leucaena leucocephala (Lam.) R. de Wit.] sobre as plantas daninhas picão-preto (Bidens pilosa L.) e caruru (Amaranthus viridis L.), a fitotoxidade dos extratos, nas concentrações de $50 \%$ e $100 \%$, ocasionaram redução significativa do crescimento e deformação do limbo foliar das plântulas analisadas (Figura 4).

FIGURA 4: Fitotoxicidade do extrato de leucena [Leucaena leucocephala (Lam.) R. de Wit.] sobre picão (Bidens pilosa L.) (a) e caruru (Amaranthus viridis L.) (b). Detalhe quanto ao aumento dos sintomas nas folhas em resposta ao aumento das concentrações do extrato. Extraído de Pires et al. (2001).
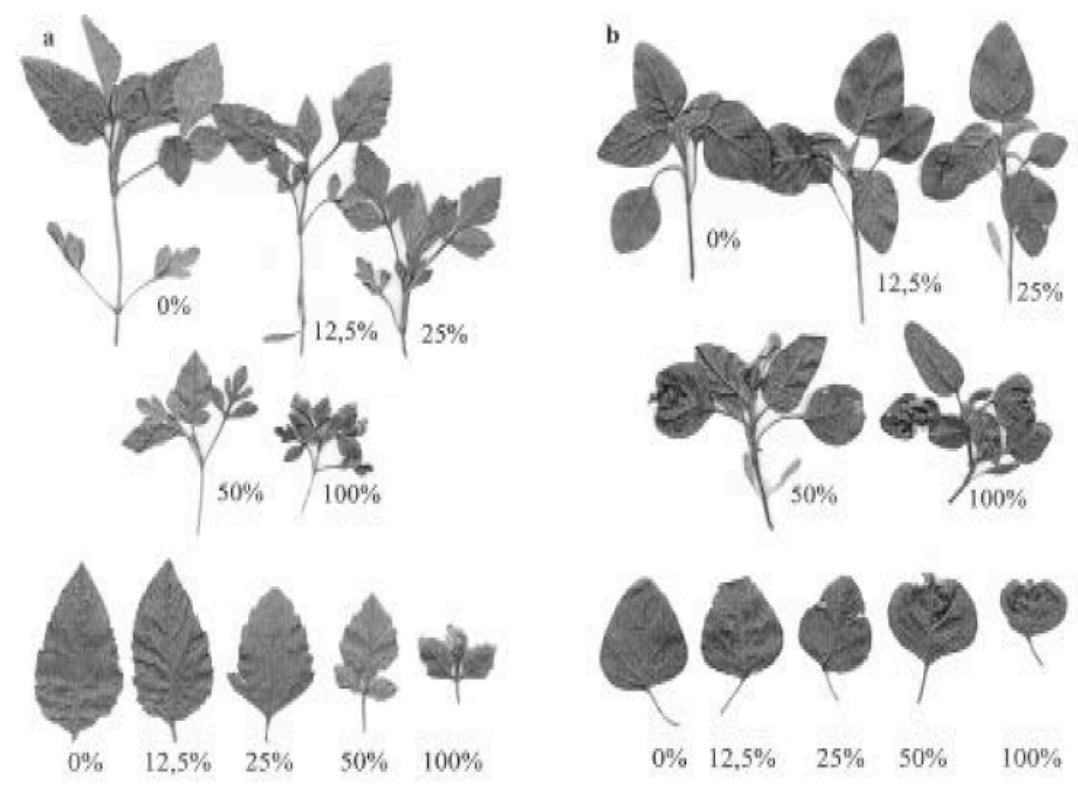
Efetuando análise do extrato de leucena por HPLC (Cromatografia Líquida de Alta Eficiência), Pires et al. (2001) identificaram diferentes concentrações do aleloquímico mimosina que, provavelmente, ocasionou o efeito fitotóxico nas plantas estudadas.

Aplicando extrato de nim sobre sementes de picão-preto, Rickli et al. (2011) verificaram diminuição significativa da germinabilidade das mesmas nas concentrações de extrato a $80 \%$ e $100 \%$. O tempo médio de germinação também foi influenciado significativamente pelo extrato bruto $(100 \%)$ e a velocidade de germinação por todas as concentrações de extrato, ao passo que o comprimento das raízes sofreu interferência a partir do extrato com $40 \%$ de concentração (Tabela 2).

Estudando a bioatividade do óleo essencial de pimenta-longa (Piper hispidinervium C. DC) e oriza (Pogostemon heyneanus Benth) sobre as invasoras malícia (Mimosa pudica L.) e mata-pasto (Senna obtusifolia L.), Souza-Filho et al. (2009) verificaram que os efeitos inibitórios exercidos pela pimentalonga foram mais acentuados quando comparados aos efeitos causados pela oriza, além disso, salientaram que, conforme se aumentou as concentrações dos óleos essenciais aplicados, inibições crescentes foram sempre obtidas e, invariavelmente, as inibições totais foram sempre observadas nas concentrações mais elevadas, ao passo que a espécie malícia foi a que apresentou maior sensibilidade aos efeitos potencialmente alelopáticos.

Outra opção para o combate de plantas invasoras é através da utilização de cobertura vegetal verde ou morta, que pode ser bastante eficiente no controle das mesmas (FERREIRA; ÁQUILA, 2000). Como verificado por Moraes et al. (2010) utilizando palhas de nabo-forrageiro (Raphanus sativus L.) e canola (Brassica napus L. Var. oleifera) sobre o solo, que reduziram o crescimento das plantas de picão-preto (Bidens sp.)

Em Marília - SP, as coberturas de solo (serragem, casca de arroz, maravalha e capim seco) em cultivo de cenoura (Daucus carota L.), no verão, apresentaram controle efetivo de beldroega (Portulaca oleracea L.), e as coberturas de serragem, capim seco e maravalha reduziram significativamente a germinação das sementes de capim-pé-de-galinha (Eleusine indica L.), também, em cultivo de cenoura (RESENDE et al., 2005) (Tabela 3).

Em Eldorado do Sul - RS, Theisen e Vidal (1999) verificaram que quando se utiliza resíduos de aveia-preta (Avena strigosa Schreb.) como cobertura de solo, em altas concentrações, menores foram as porcentagens de emergência do capim papuã (Brachiaria plantaginea (Link) Hitch.), planta daninha nas culturas de verão em áreas do Planalto do Rio Grande do Sul (Tabela 4).

TABELA 2: Porcentagem de germinação $(\% \mathrm{G})$, tempo médio de germinação (TMG), velocidade média de germinação (VMG) e comprimento médio da raiz primaria (CMR) de sementes de picão-preto (Bidens pilosa L.) submetidas ao extrato aquoso de folhas frescas de nim (Azadirachta indica A. Juss) em diferentes concentrações. Cascavel - PR/2009. Extraído de Rickli et al. (2011).

\begin{tabular}{lcccc}
\hline Tratamento & \%G & $\begin{array}{c}\text { TMG } \\
\text { (dias) }\end{array}$ & $\begin{array}{c}\text { VMG } \\
\text { (sementes/dia) }\end{array}$ & $\begin{array}{c}\text { CMR } \\
\text { (cm) }\end{array}$ \\
\hline Testemunha & $79 \mathrm{a}$ & $3,74 \mathrm{~b}$ & $0,2679 \mathrm{a}$ & $4,20 \mathrm{a}$ \\
$20 \%$ & $81 \mathrm{a}$ & $5,48 \mathrm{ab}$ & $0,1855 \mathrm{~b}$ & $3,06 \mathrm{a}$ \\
$40 \%$ & $76 \mathrm{a}$ & $6,74 \mathrm{ab}$ & $0,1584 \mathrm{bc}$ & $1,74 \mathrm{~b}$ \\
$60 \%$ & $53 \mathrm{ab}$ & $7,80 \mathrm{ab}$ & $0,1328 \mathrm{bc}$ & $0,68 \mathrm{~b}$ \\
$80 \%$ & $7 \mathrm{c}$ & $7 \mathrm{ab}$ & $0,0812 \mathrm{c}$ & $0,47 \mathrm{~b}$ \\
$100 \%$ & $12 \mathrm{bc}$ & $9,78 \mathrm{a}$ & $0,1024 \mathrm{c}$ & $0,44 \mathrm{~b}$ \\
\hline C. V. $\%$ & 31,96 & 3,76 & 23,05 & 33,10 \\
\hline
\end{tabular}

Médias seguidas da mesma letra na coluna não diferem entre si pelo teste de Tukey, a $5 \%$ de probabilidade.

C. V. \%= coeficiente de variação. 
TABELA 3: Quantidade de plantas daninhas (número de plantas $/ \mathrm{m} 2$ ) em cultura de Daucus carota L., segundo o uso de diferentes tipos de cobertura morta sobre o solo a 20 e 45 dias após a semeadura (DAS). Universidade de Marília, Marília - SP, 1999. Extraído de Resende et al. (2005).

\begin{tabular}{|c|c|c|c|c|c|c|}
\hline \multicolumn{7}{|c|}{ Incidência de plantas daninhas $\left(n^{0}\right.$ plantas $\left./ \mathbf{m}^{2}\right)-20$ DAS } \\
\hline Cobertura do solo & $\begin{array}{c}\text { Portulaca } \\
\text { oleracea }\end{array}$ & Bidens pilosa & $\begin{array}{c}\text { Eleusine } \\
\text { indica }\end{array}$ & $\begin{array}{c}\text { Amaranthus } \\
\text { lividus }\end{array}$ & $\begin{array}{c}\text { Brachiaria } \\
\text { plantaginea }\end{array}$ & Total \\
\hline Sem cobertura & $52,75 \mathrm{a}$ & $10,50 \mathrm{a}$ & $25,00 \mathrm{a}$ & $1,00 \mathrm{a}$ & $1,00 \mathrm{a}$ & $90,25 \mathrm{a}$ \\
\hline Serragem & $12,75 \mathrm{~b}$ & $5,75 \mathrm{a}$ & $6,25 \mathrm{a}$ & $0,75 \mathrm{a}$ & $0,00 \mathrm{a}$ & $25,50 \mathrm{bc}$ \\
\hline Casca de arroz & $10,75 \mathrm{~b}$ & $9,25 \mathrm{a}$ & $26,25 \mathrm{a}$ & $0,00 \mathrm{a}$ & $0,25 \mathrm{a}$ & $16,50 \mathrm{~b}$ \\
\hline Maravalha & $2,25 \mathrm{~b}$ & $5,50 \mathrm{a}$ & $5,75 \mathrm{~b}$ & $0,00 \mathrm{a}$ & $0,25 \mathrm{a}$ & $13,75 \mathrm{c}$ \\
\hline Capim seco & $3,75 \mathrm{~b}$ & $7,50 \mathrm{a}$ & $1,50 \mathrm{~b}$ & $0,00 \mathrm{a}$ & $0,25 \mathrm{a}$ & $13,00 \mathrm{c}$ \\
\hline \multicolumn{7}{|c|}{ Incidência de plantas daninhas $\left(n^{0}\right.$ plantas $\left./ m^{2}\right)-45$ DAS } \\
\hline Sem cobertura & $30,50 \mathrm{a}$ & $4,75 \mathrm{bc}$ & $12,25 \mathrm{a}$ & $0,00 \mathrm{~b}$ & $1,25 \mathrm{a}$ & $48,75 \mathrm{a}$ \\
\hline Serragem & $10,25 \mathrm{~b}$ & $5,50 \mathrm{ab}$ & $9,50 \mathrm{ab}$ & $0,00 \mathrm{~b}$ & $0,25 \mathrm{a}$ & $25,50 \mathrm{~b}$ \\
\hline Casca de arroz & $7,75 \mathrm{~b}$ & $7,75 \mathrm{a}$ & $4,75 \mathrm{bc}$ & $1,50 \mathrm{a}$ & $1,50 \mathrm{a}$ & $23,25 \mathrm{bc}$ \\
\hline Maravalha & $8,00 \mathrm{~b}$ & $3,00 \mathrm{bc}$ & $3,00 \mathrm{bc}$ & $0,00 \mathrm{~b}$ & $0,00 \mathrm{a}$ & $14,00 \mathrm{bc}$ \\
\hline Capim seco & $6,00 \mathrm{~b}$ & $2,25 \mathrm{c}$ & $2,50 \mathrm{~b}$ & $0,50 \mathrm{ab}$ & $0,00 \mathrm{a}$ & $11,25 \mathrm{c}$ \\
\hline
\end{tabular}

Médias seguidas pelas mesmas letras nas colunas não diferem entre si, pelo teste de Duncan, a 5\% de probabilidade.

TABELA 4: Emergência de sementes de papuã [Brachiaria plantaginea (Link) Hitch.] de 0 a 97 dias após o manejo da palha de aveia-preta (Avena strigosa Schreb) sobre o solo, em cinco níveis de palha (cobertura vegetal). Estação Experimental Agronômica da Universidade Federal do Rio Grande do Sul, Eldorado do Sul, RS, 1997. Extraído de Theisen e Vidal (1999).

\begin{tabular}{cc}
\hline Cobertura vegetal (t/ha) & Emergência $^{\mathbf{~}} \mathbf{( \% )}$ \\
\hline 0,0 & 4,47 \\
2,6 & 1,23 \\
5,4 & 0,18 \\
7,8 & 0,29 \\
10,5 & 0,08 \\
\hline
\end{tabular}

${ }^{1}$ Dias após o manejo da palha sobre o solo; ${ }^{2}$ Banco de sementes com 34.719 sementes $/ \mathrm{m}^{2}$, até $9 \mathrm{~cm}$. t/ha: Toneladas por hectare.

Em Uberlândia - MG, Correia et al. (2006) verificaram que aos 75 dias após a quantificação do equivalente de palha por hectare de diferentes resíduos vegetais, houve uma diminuição do número de plântulas de picão-preto (Bidens pilosa L.) no maior nível de palha de sorgo (Sorghum bicolor $x$ S. sudanensis 'Cober Exp') (5,5t.ha-1), nos dois níveis de palha de capim-pé-de-galinha [Eleusine coracana (L.) Gaertn.] $\left(3,0\right.$ e 5,5t.ha $\left.{ }^{-1}\right)$ e no menor nível de palha de braquiária
(Brachiaria brizantha (Hochst.) Stapf.) (3,0t.ha $\left.{ }^{-1}\right)$ que, consequentemente, refletiu no acúmulo de matéria seca das plantas de picão-preto (Tabela 5).

É importante ressaltar que o potencial alelopático da cobertura vegetal depende da quantidade de resíduo vegetal utilizado, do tipo de substância que é liberada no solo e do tipo de plantas daninhas que ali se desenvolvem, o que torna a escolha do material vegetal a ser utilizado de extrema importância, uma vez que, em quantidades similares, há respostas distintas entre as coberturas para uma mesma espécie de planta daninha (TOKURA; NÓBREGA, 2006; MORAES et al., 2010), como pode ser verificado na Tabela 5 .

Com isso, é possível perceber que os procedimentos experimentais de alelopatia geram contribuições para os estudos de dinâmica entre espécies vegetais e para a elaboração de estratégias alternativas de produção e manejo de culturas (SOUZA-FILHO et al., 2010), através da escolha de espécies que reduzam os custos de produção, da diminuição do uso de defensivos químicos, amenizando os impactos que os mesmos causam no ecossistema (GOLDFARB et al., 2009), e para a prática de uma agricultura sustentável. 
TABELA 5: Emergência e acúmulo de matéria seca de plantas de picão-preto (Bidens pilosa L.) submetidas a quatro tipos de cobertura vegetal em dois níveis de palha. Uberlândia-MG, 2003/2004. Adaptado de Correia et al. (2006).

\begin{tabular}{|c|c|c|c|c|}
\hline \multirow{3}{*}{ Tipo de cobertura } & \multicolumn{2}{|c|}{$\begin{array}{c}\text { Número de plântulas } \mathrm{m}^{-2} \\
75 \text { DAQ }\end{array}$} & \multicolumn{2}{|c|}{$\begin{array}{c}\text { Matéria seca }\left(\mathrm{g} \mathrm{m}^{-2}\right) \\
75 \text { DAQ }\end{array}$} \\
\hline & \multicolumn{4}{|c|}{$\begin{array}{l}\text { Níveis de palha }\left(\mathrm{t} \mathrm{ha}^{-1}\right) \\
\end{array}$} \\
\hline & 3,0 & 5,5 & 3,0 & 5.5 \\
\hline Sorgo & $107,0 \mathrm{~b} \mathrm{~B}$ & 2,0 a A & $94,28 \mathrm{ab} \mathrm{A}$ & 47,80 a A \\
\hline Milheto forrageiro & $108,0 \mathrm{~b} \mathrm{~A}$ & $81,0 \mathrm{~b} \mathrm{~A}$ & $167,20 \mathrm{~b} \mathrm{~A}$ & 190,16 b A \\
\hline Capim-pé-de-galinha & 42,0 a A & 17,0 a $\mathrm{A}$ & 39,00 a A & 20,80 a A \\
\hline Braquiária & 51,0 a $\mathrm{A}$ & $120,0 \mathrm{~b} \mathrm{~B}$ & 38,68 a B & $251,84 \mathrm{~b} \mathrm{~A}$ \\
\hline DMS (na linha) & \multicolumn{2}{|c|}{2,56} & \multicolumn{2}{|c|}{97,34} \\
\hline DMS (na coluna) & \multicolumn{2}{|c|}{3,10} & \multicolumn{2}{|c|}{122,67} \\
\hline Testemunha sem palha & \multicolumn{2}{|c|}{286,0} & \multicolumn{2}{|c|}{180,44} \\
\hline
\end{tabular}

$\mathrm{DAQ}=$ dias após a quantificação da palha. DMS= diferença média significativa. Com base no teste de Tukey a 5\% de probabilidade, médias seguidas por letras minúsculas, nas colunas, comparam os tipos de cobertura dentro de cada nível de palha, e por letras maiúsculas, nas linhas, os dois níveis para cada cobertura. Calcularam-se as médias do número de plântulas obtidas e, em seguida, as mesmas foram transformadas em $(x+0,5) \frac{1}{2}$ para a realização da análise estatística.

\section{Referências}

ALMEIDA, F. S. A alelopatia e as plantas. Londrina: IAPAR, 1988. 60 p. (Circular, 53).

AlmeidA, F. de A. C.; GOLDFARB, A. N.; GOUVEIA, J. P. G. de. Avaliação de extratos vegetais e métodos de aplicação no controle de Sitophillus spp. Revista Brasileira de Produtos Agroindustriais, Campina Grande, v. 1, n. 1, p. 13-20, 1999.

AlMEIDA, G. D. de; ZUCOlOTO, M.; ZETUN, M. C.; COELHO, I.; SOBREIR, F. M. Estresse oxidativo em células vegetais merdiante aleloquímicos. Revista Facultad Nacional de Agronomia, Medellín, v. 61, n. 1, p. 4237-4247, 2008.

AMARAL, D. F.; OLIVEIRA, D. F.; CAMPOS, V. P.; CARVALHO, D. A. Efeito de alguns extratos vegetais na eclosão, mobilidade, mortalidade e patogenicidade de Meloidogyne exigua do cafeeiro. Nematologia Brasileira, Piracicaba, v. 26, n. 1, p. 43-48, 2001.

APPLETON, B.; BERRIER, R. The walnut tree: allelopathic effects and tolerant plants. Virginia: College Of Agriculture And Life Sciences, Virginia Polytechnic Institute And State University, 2009. Disponível em <http://pubs.ext. vt.edu/430/430-021/430-021_pdf.pdf $>$. Acesso em: 23 junho 2011.

BArbosa, L. C. A.; MALThA, C. R. A.; DEMUNER, A. J.; GANEM, F. R. Síntese de novas fitotoxinas derivadas do 8-oxabiciclo[3.2.1] oct-6-en-3-ona. Química Nova, São Paulo, v. 28, n. 3, p. 444-450, 2005.

CORREIA, N. M.; DURIGAN, J. C.; KLINK, U. P. Influência do tipo e da quantidade de resíduos vegetais na emergência de plantas daninhas. Planta Daninha, Viçosa, v. 24, n. 2, p. 245-253, 2006.

CORSATO, J. M.; FORTES, A. M. T.; SANTORUM, M.; LESZCZYNSKI, R. Efeito alelopático do extrato aquoso de folhas de girassol sobre a germinação de soja e picão-preto. Semina: Ciências Agrárias, Londrina, v. 31, n. 2, p. 353-360, 2010.
FERREIRA, A. G.; AQUILA, M. E. A. Alelopatia: Área emergente da ecofisiologia. Revista Brasileira de Fisiologia Vegetal, Campinas, v. 12, (Edição Especial), p. 175-204, 2000.

FERREIRA, A. G.; BORGHETTI, F. Germinação: do básico ao aplicado. Porto Alegre: Artmed, 2004. 323 p.

FRANÇA, A. C.; SOUZA, I. F. de; ALVES, L. A. R.; LIMA, R. R. de; OLIVEIRA, E. Q. de. Efeitos de restos culturais de milho no desenvolvimento inicial de cafeeiros Scientia Agraria, Curitiba, v. 8, n. 3, p. 247-255, 2007.

GOLDFARB, M.; PIMENTEL, L. W.; PIMENTEL, N. W. Alelopatia: relações nos agroecossistemas. Tecnologia \& Ciência Agropecuária, João Pessoa, v. 3, n. 1, p. 23-28, 2009.

MAIRESSE, L. A. S.; COSTA, E. C.; FARIAS, J. R.; FIORIN, R. A. Bioatividade de extratos vegetais sobre alface (Lactuca sativa L.). Revista da FZVA, Uruguaiana, v. 14, n. 2, p. 1-12. 2007.

MORAES, P. V. D. de; AGOSTINETTO, D.; PONAZZO, L. E. P.; BRANDOLT, R. R.; TIRONI, S. P.; OLIVEIRA, C.; MARKUS, C. Efeito alelopático de plantas de cobertura, na superfície ou incorporadas ao solo, no controle de picão-preto. Revista da FZVA, Uruguaiana, v. 7, n. 1, p. 51-67, 2010.

NEVES, R. Potencial alelopático da cultura da canola (Brassica napus L. Var. Oleifera) na supressão de picão-preto (Bidens sp.) e soja. 2005. 87 f. Dissertação (Mestrado Agronomia/Produção Vegetal) - Universidade de Passo Fundo, Passo Fundo, 2005.

PIÑA-RODRIGUES, F. C. M.; LOPES, B. M. Potencial alelopático de Mimosa caesalpinaefolia Benth sobre sementes de Tabebuia alba (Cham.) Sandw. Floresta e Ambiente, Seropédica, v. 8, n. 1, p. 1-10, 2001.

PIRES, N. de M.; PRATES, H. T.; FILHO, I. A. P.; JR OLIVEIRA, R. D. de; FARIA, T. C. L. Atividade alelopática da leucena sobre espécies de plantas daninhas. Scientia Agricola, Piracicaba, v. 58, n. 1, p. 61-65, 2001. 
RAZAVI, S. M. Plant coumarins as allelophatics agents. International Journal of Biological Chemistry, Pakistan, v. 5, n. 1, p. 86-90, 2011.

REIGOSA, M. J.; PEDROL, N.; GONZÁLEZ, L. Allelopathy: a physiological process with ecological implications. Holanda: Springer, 2006, p. 127-139.

RESTELlO, R. M.; MENEGATT, C.; MOSSI, A. J. Efeito do óleo essencial de Tagetes patula L. (Asteraceae) sobre Sitophilus zeamais Motschulsky (Coleoptera, Curculionidae). Revista Brasileira de Entomologia, Curitiba, v. 53, n. 2, p. 304-307, 2009.

RESENDE, F. V.; SOUZA, L. S. de; OLIVEIRA, P. S. R. de; GUALBERTO, R. Uso de cobertura morta vegetal no controle da umidade e temperatura do solo, na incidência de plantas invasoras e na produção da cenoura em cultivo de verão. Ciência e Agrotecnologia, Lavras, v. 29, n. 1, p. 100-105, 2005.

REZENDE, C de P.; PINTO, J. C.; EVANGELISTA, A. R.; SANTOS, I. P. A. Alelopatia e suas interações na formação e manejo de pastagens plantas forrageiras. Lavras: UFLA, 2003. 18 p. (Boletim Agropecuário).

RICKLI, H. C.; FORTES, A. M. T.; SILVA, P. S. S.; PILATTI, D. M.; HUTT, D. R. Efeito alelopático de extrato aquoso de folhas de Azadirachta indica A. Juss. em alface, soja, milho, feijão e picãopreto. Semina: Ciências Agrárias, Londrina, v. 32, n. 2, p. 461 $-472,2011$.

RIZVI, S. J. N.; RIZVI, V. Allelopathy: basic and applied aspects. London: Chapman \& Hall, 1992. 480 p.

SEVERINO, L. S.; LIMA, R. de L. S. de L.; ALBUQUERQUE, R. C. Alelopatia de plantas daninhas sobre mamona. 2008. Disponível em: <http://www.cnpa.embrapa.br/produtos/mamona/ publicacoes/trabalhos_cbm2/061.pdf. $>$. Acesso em: 20 setembro 2011.
SCHIEDECK, G. Aproveitamento de plantas bioativas: estratégia e alternativa para a agricultura familiar. 2008. Disponível em $<$ http://www.cpact.embrapa.br/imprensa/artigos/2008/artigo\%20 Gustavo_bioativ.pdf.>. Acesso em: 07 fevereiro 2012.

SOUZA-FILHO, A. P. da S. Alelopatia e as plantas. Belém: Embrapa Amazônia Oriental, 2006. 159 p.

SOUZA-FILHO, A. P. da S.; GUILHON, G. M. S. P.; SANTOS, L. S. Metodologias empregadas em estudos de avaliação da atividade alelopática em condições de laboratório - revisão crítica. Planta Daninha, Viçosa, v. 28, n. 3, p. 689-697, 2010.

SOUZA-FILHO, A. P. da S.; VASCONCELOS, M. A. M. de; ZOGHBI, M. das G. B.; CUNHA, R. L. Efeitos potencialmente alelopáticos dos óleos essenciais de Piper hispidinervium C. DC. e Pogostemon heyneanus Benth sobre plantas daninhas. Acta Amazonica, Manaus, v. 39, n. 2, p. 389-395, 2009.

TAIZ, L; ZEIGER, E. Fisiologia vegetal. 4 ed. Porto Alegre: Artmed, 2009, 319 p

THEISEN, G.; VIDAL, R A. Efeito da cobertura do solo com resíduos de aveia preta nas etapas do ciclo de vida do capimmarmelada. Planta Daninha, Viçosa, v. 17, n.2, p. 189-196, 1999.

TOKURA, L. K.; NÓBREGA, L. H. P. Alelopatia de cultivos de cobertura vegetal sobre plantas infestantes. Acta Scientiarum Agronomy, Maringá, v. 28, n. 3, p. 379-384, 2006.

VIANA, E. M.; SILVA, H. G.; VILLALBA, J. P.; LARA, M. A. F.; SANTINHO, R. E. Estudo do efeito alelopático da cultura de aveia sobre a cultura do milho. Projeto, Campo Grande, p. 1-5, 2001.

ZANINE, A. de M.; SANTOS, E; M. Competição entre espécies de plantas - Uma revisão. Revista da FZVA. Uruguaiana, v. 11, n. 1, p. 10-30, 2004. 